Journal of Engineering and Applied Sciences 14 (6): 1805-1812, 2019

ISSN: 1816-949X

(C) Medwell Journals, 2019

\title{
Executing Work Principle Star/Delta Starter in Motor Systemsusing Allen-Bradley PLC
}

\author{
${ }^{1}$ Ali Thaeer Hammid, ${ }^{2}$ Omar A. Imran and ${ }^{3}$ Younis Kadthem Hameed \\ ${ }^{1}$ Department of Computer Engineering Techniques, Al Yarmouk University College, \\ $32001 \mathrm{Ba}$ 'aqubah, Diyala, Iraq \\ ${ }^{2}$ Department of Chemical of Engineering, College of Engineering, \\ ${ }^{3}$ Department of Statistic, Administration and Economics College, Diyala University, \\ $32001 \mathrm{Ba}$ 'aqubah, Diyala, Iraq
}

\begin{abstract}
Practically there is no point in leave usage of Star/Delta starter control circuits in situations that include different various types of motors due to its importance to start working for specific motors at least loss of current. Nevertheless, curry out of star/delta starter control circuit on synchronous and induction generally need much more workand effortsand it is not easy to implement in general commercial workstations or remote fields. On the contrary, applied to star/delta starter control circuit inthe PLC is proposed a way to be applied and identify its componentsof this work that regard as peripherals to the PLC. Picotype of PLC will be employed for this purpose. Simplify of programming circuit written codes caused by ladder language and applied by software name's Picosoft Version 6 for this project case. Many developing countries began using PLC in its industrial field in a jiffy. In this study, there is a providing for simulation, circuit diagram and communication for star/delta starter control circuit by PLC and its result on board separately.
\end{abstract}

Key words: Star/delta starter, PLC, RS-232, Allen-Bradly, Picosoft Software, communication, simulation

\section{INTRODUCTION}

Diverse starting techniques are engaged for beginning induction and synchronous drivessince these drivespull more beginning current throughoutthe beginning. To avoida loss to the windings owing to the great beginning current stream, there is anengagement for diverse kinds of beginners. The humble procedure of drive beginner for the induction and synchronous driver is the star/delta starter beginner. Star/delta starter is to find out the best dependable and useful start process which has the fewer influence worth difficulties. These three simple start techniques which diverge in their individual cabling joining are the best appropriate and commonly used start technique in the manufacturing region owing to its financial details (Goh et al., 2009).

Star delta starter is preferred with induction/synchronous motor due to following reasons: starting current is reduced 3-4 time of the direct current due to which voltage drops and hence it causes fewer losses. Star delta starter circuit comes in circuit first during starting of the motor which reduces voltage 3 times, that is why current also reduces up to 3 times and hence, less motor burning is caused. In addition, starting torque is increased and it prevents the damage of motor winding.

In this study, firstly the illustration of the star/delta starter in general. Then programming mentioned circuit at PLC. Finally, the evaluation of viable and feasible mode is done by PLC. Where, circuit theory of star/delta starter (Goh et al., 2009; Kato et al., 2013). PLC dependable usages (Hammid et al., 2016, 2017a-c; Papa et al., 2013), description of circuit components with details ((Catalog numbers 1760-L12AWA; Bryan and Bryan et al., 1997; Dunga et al., 2014; Hammid, 2013, 2016; Hammid et al., 2013; Iovev and Yakimov, 2015) there is a described for the mechanism of interfacing between PC and PLC as well as star/delta starter implementation in picosost and finally download this code to PLC (Abdelmoumene and Bentarzi, 2014; Alexander and Matthew, 2012; Alphonsus and Abdullah, 2016; Hammid et al., 2017a-c; Mazidi, 2013; Naeem, 2009).

The concept of star/delta starter: This is a starting method that reduces the starting current and starting torque. Star delta starter design normally consists of three contactors, an overload relay and a timer for setting the

Corresponding Author: Ali Thaeer Hammid, Department of Computer Engineering Techniques, Al Yarmouk University College, 32001 Ba'aqubah, Diyala, Iraq 
time in the star-position (starting position). For the star delta starter, a motor must be in delta connected during a normal run and the main purpose is to be able to use star delta starter. Star delta starter received the starting current is about $30 \%$ of the starting current during direct online start and the starting torque is reduced to about $25 \%$ of the torque available at a D.O.L start. Star delta starter only works when the application is light loaded during the start. If the motor is too heavily loaded, there will not be enough torque to accelerate the motor up to speed before switching over to the delta position (Goh et al., 2009; Hammid et al., 2017a-c).

The basic function is to enable the motor to start and the motor windings are configured in a star formation to the supply voltage. The voltage applied for star delta starter to the individual motor winding is therefore reduced by a factor of $1 \sqrt{3}=0.58$ this connection amounts to approximately $30 \%$ of the delta values. The starting current is reduced to one-third of the direct starting current.

Due to the reduced starting torque, the star-delta connection is suitable for drives with a high inertia mass but a resistance torque which is low or only increases with increased speed. It is preferably used for applications where the drive is only put under a load after the run-up. After motor run-up in most cases, an automatic timing relay controls the switch-over from star to delta. The run-up using star connection should last until the motor has reached the approximate operational speed. So that, after switching to Delta, as little post acceleration as possible is required. Post-acceleration in delta connection will instigate high currents as seen with direct on-line starting (Hammid et al., 2017a-c; Kato et al., 2013).

Programmable Logic Controller (PLC) usage: There is a settled in a rule of automation at its water usage stations. Originally built on hard logic units, the knowledge used was upgraded, upgraded and improved in the late seventies by the liberal and wide use of Programmable Logical Controllers (PLC). Thedrinking water creation of the wastedarea of Paris ( 1 million dwellers) has been completelyautomatic (with around 100 PLCs) and unmanned next hours (Hammid et al., 2016). The refinement of water for internal drinking includes numerous steps of dealingwith the raw water which isessential to eliminate postponed objects, color and bacteria previously being supplied to the water delivery system. The viability of automating the control and cleaning of the filters through the request of a suitable PLC foundedplan (Hammid et al., 2017a-c). The skills of Bechtel Water Technology Engineering, at the request of programmable logic controllers to schemes which were considered and built on behalf of the main water and unused water value (Hammid and Sulaiman, 2017; Papa et al., 2013).

A method for development of such system network using potentials of the Programmable Logic Controller (PLC) is a getaway (Hammid and Sulaiman., 2017; Iovev and Yakimov, 2015). Nevertheless, curry out of DOL and its reverse on synchronous and induction generally need much more works and efforts and it is not easy to implement in general commercial workstations or remote fields. On contrary, applied of DOL and R-DOL in $\mathrm{PLC}$ is proposed a way to be applied and identify of its components in this research that regard as peripherals to PLC (Hammid, 2016; Hammid and Sulaiman, 2017). Obviously, there are almost control fields that PLCs endure and employ in it, like home automation control (Hammid et al., 2013). Recently it's used for regulation of power production in power plants for turbine and generator (Hammid, 2013; Hammid et al., $2017 \mathrm{a}-\mathrm{c})$.

Execution circuits components description: A Programmable Logic Controller (PLC) or programmable controller is a digital computer employed for automation of normally engineering electro-mechanical procedures, like a regulator of equipment on factory gathering outlines, enjoyment rides or light matches. PLCs are employed in numerousmachinery in numerous businesses. PLCs are planned for several engagements of digital and analog inputs and outputs, lengthy temperature varieties, immunity to electrical noise and resistance to shaking and impact. Plans to control engineprocess are naturally kept in battery-backed-up or non-volatile memory. A PLC is asample of a "hard" real-time system due to output effects have to be created in reply to input situations within a restrict edperiod; else unplanned process would outcome (Bryan et al., 1997; Dunga et al., 2014).

A relay is an electrically activatedkey. Numerous relays employ an electro magnet to mechanically activate a key but extra working values are also employed, like solid-state relays. Relays are employed when there is essential to control a circuit by a low-power signal (with whole electrical isolation between control and controlled circuits) or where numerous circuits must be controlled by a lone signal. The first relays were employed in long expanse telegraph circuits as amplifiers: they regular the signal coming in from one circuit and re-transmitted it on another circuit. Relays were employedwidely in receiver contacts and quick processes to achieve logical processes (Abdelmoumene and Bentarzi, 2014; Hammid et al., 2017a-c). 
A Normally Open (NO) impulse key is an impulse key that in its evasionpublic, creates no electrical contact with the circuit. Just if the key is pushed down, it does make electrical contact with the circuit. If the key is pressed down, the key makes electrical contact and the circuit is now locked. Thus, electricity can now stream to the new portion of the circuit joining to the push key and make the device turn or power on the respective portion. Normally open impulsekeys are the great estpublic kind of push keys used in devices and circuits. A Normally Closed (NC) impulse Key is animpulse key that in its evasionnational, makes electrical contact with the circuit. When the key is pushed down, the key no longer makes electrical contact and the circuit is now open. Thus, electricity has no longer stream to the added portion of the circuit to turn or power on the respective portion of the circuit the key was made to switch. Normally closed push keys are not the great estpublic kind of push key used; Normally open push keys are. Nevertheless, they still have general use and request in several strategies (Alexander and Matthew, 2012; Hammid, 2013; Hammid et al., 2017a-c; Naeem, 2009).

RS-232 stands for recommend standard number 232 and $\mathrm{C}$ is the latest revision of the standard. The serial ports on most computers use a subset of the RS-232 C standard. The full RS-232C standard specifies a 25-pin "D" connector of which 22 pins are used. Most of these pins are not needed for normal PC communications and indeed, most new PCs are equipped with male D type connectors having only 9 pins (Hammid et al., 2017a-c; Mazidi, 2013).

PLC to PC connection and interfacing: The period logic is employed, since, the programming is mainly concerned with applying logic and changing processes. Input devices such as switches and output devices such as drives, being controlled are connected to the PLC and then the controller displays the inputs and outputs agreeing to the machine or process. Originally PLCs were planned as an extra for hard-wired relay and timer logic control systems. (Hard-wiring means that all of the components were manually connected by wires). PLC contains two parts i.e., the PLC hardware and programming (Alphonsus and Abdullah, 2016; Hammid et al., 2017a-c).

The proposed device using is Programmable Logic Control (PLC) from Rock Well Allen-Bradly, it specific model is (Pico 1760-L12 AWA-ND) as displayed in Fig. 1 Firstly, there are two usages groups of a bush button like Normally Open (N.O) in green color and Normally Close (N.C) in red color and it is represented to the input signal. Where these bush buttonsare wiring to PLC inputs. PLC

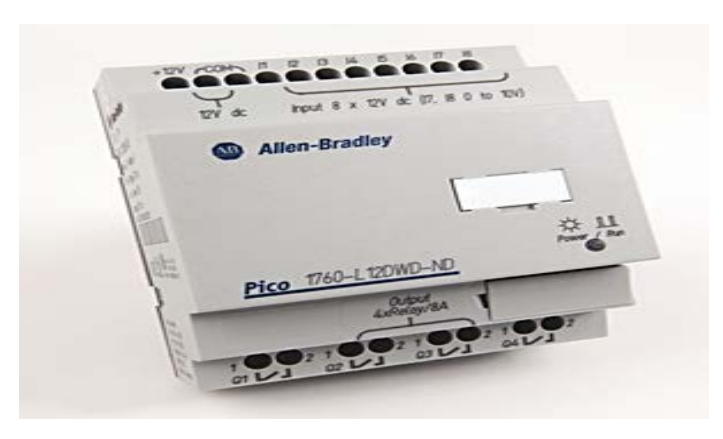

Fig. 1: PLC/Pico 1760-L12 AWA-ND

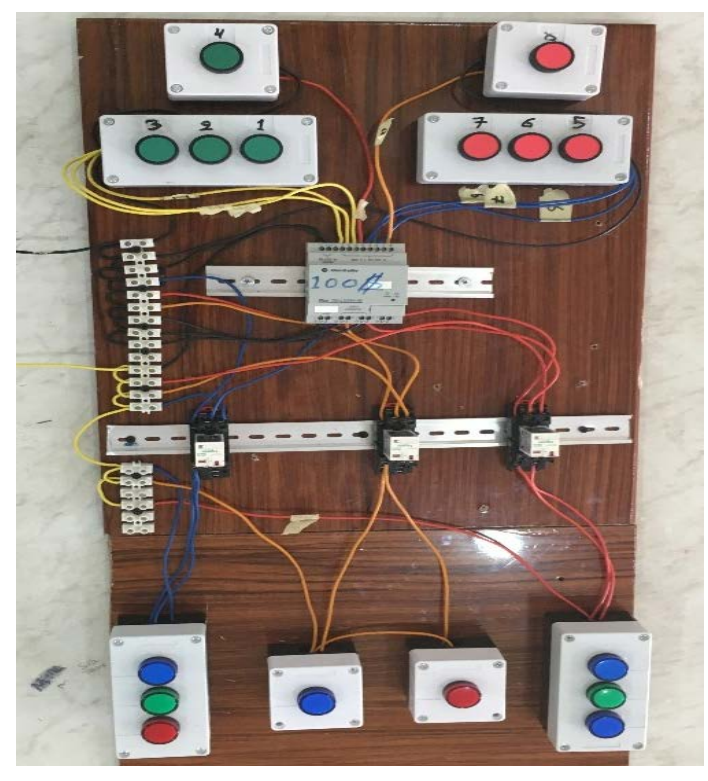

Fig. 2: Electrical control panel

Allen-Bradley from Rock-Well is working on $220 \mathrm{~V}$ directly, so that, it is employed to this function properly. The proposed circuit panelalso contains $220 \mathrm{~V}$ relay coil that is wiring also to PLC output, this is control circuit output. There are three color signal light bulbs and it represents to output and is connected to power circuit on output as displayed in Fig. 2.

Next, the proposed software usage is picosoft Vision 6 that let us program PLC by using ladder language due to it is specific software for this version of PLC/Pico. RS 232 connector and its cable areto make Simulink and download connection between PC and PLC. Finally, the connection between PLC and PC is done by using the serial port and RS 232 cable physically.

\section{MATERIALS AND METHODS}

Execution proposed of star/delta starter circuit logically: The ladder language has made a good job for it 


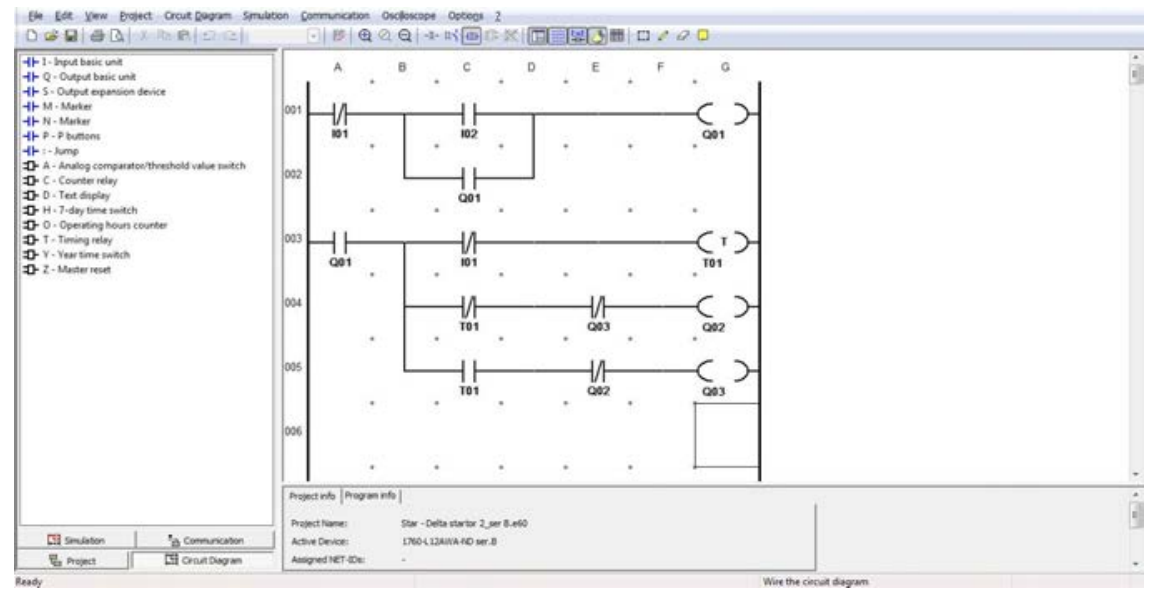

Fig. 3: Star/delta starter diagram by Picosoft's

obliviously, since, it did not interest in the difficulty of the diagram but it makes them easier more and more. By the sound of it, there is no point in leave ladder language and it not is bound to any limit. By using ladder language, it has been accomplished by the programming the star/delta starter circuit. Explain circuit diagram is consisting of 2 logical switches.

Logical switch number 2 at Picosoft Software is Normally Open (N.O) and it is used for start working on the circuit to let it start accounting for star connection. whereas it is N.O, so, as to it does not let power through it directly as soon as it has not power signal from outside switch that connectsto position 2 in PLC. On contrary when this logical switch gets signal power from position 2 in PLC it would get circuit on.

Logical switch number 1 at Picosoft Software is Normally Close (N.C) is used for resetting the circuit to let it start over again. Whereas it is N.C, so as not to let power through it directly as soon as it gets signal power from position 1 in PLC. On contrary, this logical switch let the signal power to through in it when there is no signal power from output switch that connected in position 1 in PLC.

Due to logical output number 1 at Picosoft Software is connected to logical switch number 2 in parallel connection to let the power go through in it when logic switch number 2 is cut it off and has the ability of continuation on output as displayed in Fig. 3.

Obviously, logical output at Picosoft Software are three outputs for proposed system and it is employed as a controloutput logical address. Second of these outputs is providing an output signal to star power circuit at first $5 \mathrm{sec}$ and then will cut off, third of these outputs is providing an output signal to delta power circuit at end of $5 \mathrm{sec}$ and then will power on to infinite. First of output is providing timer delay output that would be work at two cases star period and delta period.
Timing delay is an on-delayed timer type and it employed for purpose of delay period between star and delta. And there is only one logic timer used at Picosoft Software. It is a timer on the type that gives power for a delay period and cut power off after a delay period. Delay period used is $5 \mathrm{sec}$ only. Actually, there is only one-time delay but it is employed for several users. One time is used as Normally Close (N.C) and connect it in star timer output circuit, it let the power to through in it and give power to star timer, so that, star output is work for first $5 \mathrm{sec}$. The second time is used as Normally Open (N.O) and connect it in delta timer output circuit, it doesn't let the power go through in it at $5 \mathrm{sec}$ and then gives power to delta timer, so that, delta output is work for end $5 \mathrm{sec}$ or after $5 \mathrm{sec}$ as displayed in Fig. 3.

Operation simulations and simulation page at Picosoft Software and see power position stop, before logical switches that need to getasignal power form hardware panel push bottom to start work, as displayed in Fig. 4.

The logical switch normally open has address number 2 is connected on an electrical panel with push button normally open has address number 2 due to it is connected to position 2 in PLC as shown in Fig. 2. Thus, when the worker press push button number 2 on electrical panel, it let the power go through and get output on other hand push button switch number 2 on electrical panel give power signal to logic switch number 2 on Picosoft Software to let signal input power make timer to start accountingas well as it represents the prime part working and working motor at star circuit only at first $5 \mathrm{sec}$ period only as displayed in Fig. 5.

Afterwards, the same worker press push button number 2 on electrical panel lets signal input power make 


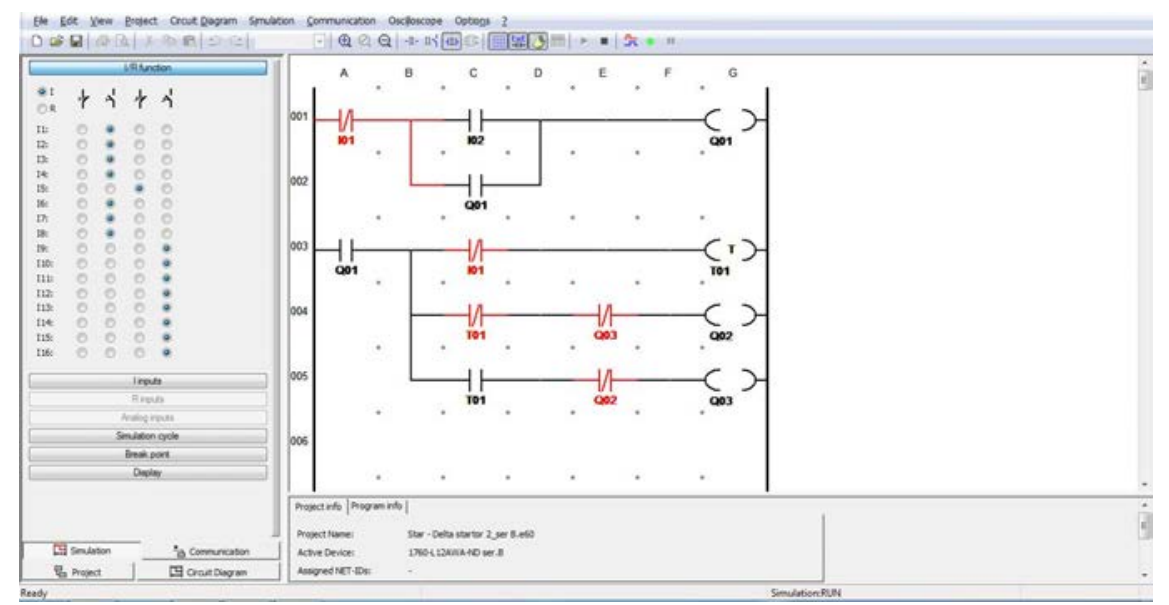

Fig. 4: Operation simulation without power signal output

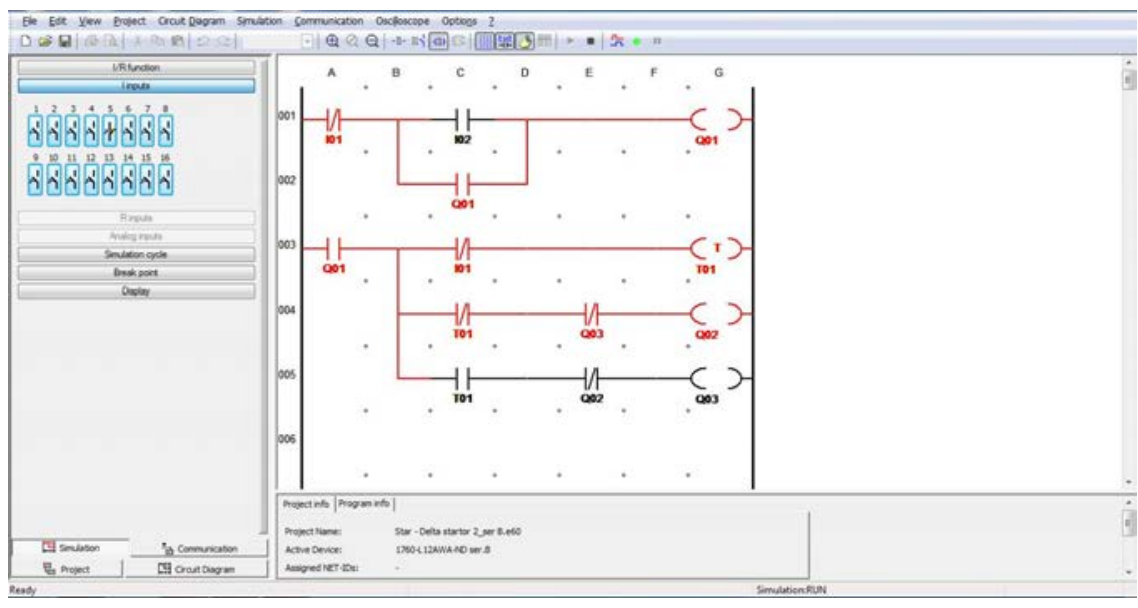

Fig. 5: Operation simulation with starpower signal output

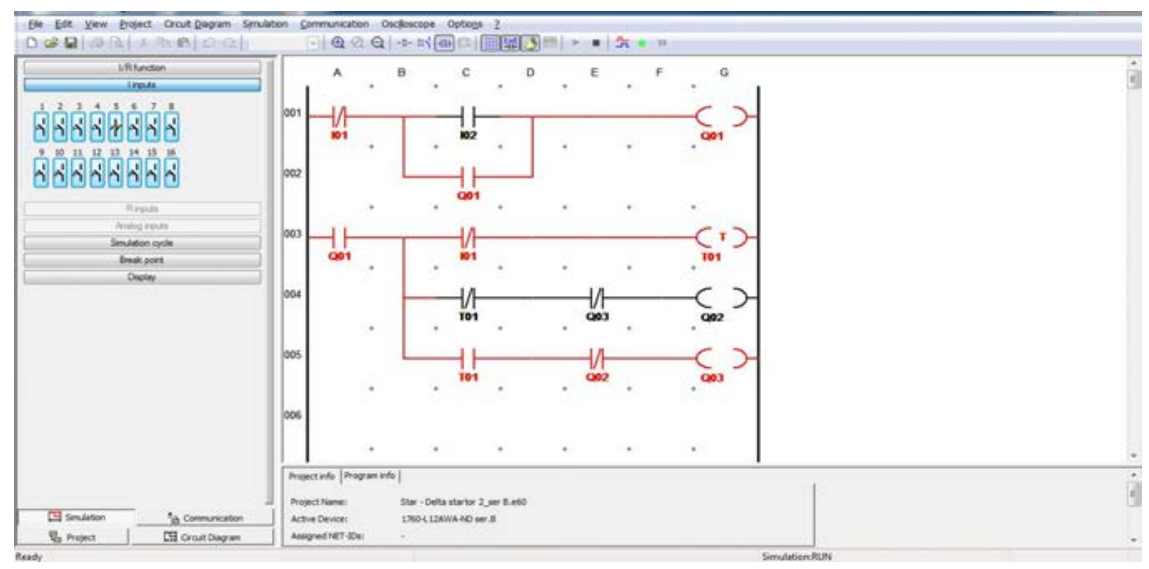

Fig. 6: Operation simulation with delta power signal output

timer to delta accounting after $5 \mathrm{sec}$ on another hand after end of star time as well as it represents the second part working and working motor at delta circuit after finish of $5 \mathrm{sec}$ period to infinite time as displayed in Fig. 6. 
At Picosoft Software, logical switch normally close has address number 1 is connected to an electrical panel with push button normally open has address number 1due to it is connected to position 1 in PLC. Thus, when the worker press push button number 1 on the electrical panel, it let the power to be cut off instantaneously and reset the circuit as displayed in Fig. 5. Now, the worker can return the circuit operation again and can make a reset and return circuit for all operations as the worker needs.

As illustrated before, the timer address in Picosoft Software has to divided into two categories; one of these logical addresses is put it on Normally Close (N.C) logical switch made a let the power signal pass through at first 5 sec when the timer is accounting for star connection circuit. Then second logical addresses are put it on Normally Open (N.O) logical switch made to let the power signal pass through after finish $5 \mathrm{sec}$ (period of star connection) when the timer is finished accounted for star circuit to make delta connection circuit work on.

Moreover, in this study, there was made a security mode by using 2 logical switches normally close put it before outputting at Picosoft Software. First one has the address of output 2 and it has a name of delta circuit, so as to be cut power off on output 1 when output 2 is work on. On contrary second one has the address of output 1 and it has the name of star circuitso as to be cut power off on output 2 when output 1 is work on as displayed in Fig. 5.

\section{RESULTS AND DISCUSSION}

There is an important alarm checking for accreted connection properly between PLC and PC and check the right code downloaded through it by note blink yellow bulb at the middle of PLC. When the worker starts power on, the motor is stand by, in safety mode and don't rotate. Whereas the worker can notice bulb for first output and the second output is signaling and indicating to power off as displayed in Fig. 7.

When the worker press push button 2 on the electrical panel, the motor starts rotation and working in a star connection. Where as the worker can notice bulb for timer delay signal is indicating to power on and bulb for first output is signaling to power on and bulb for second output is signaling to power off as displayed in Fig. 8.

The previous period is representing star connection. Now the period represents for delta connection circuit where it's done without press any push button. When the time delay is finished accounting, the circuit is converted to the delta connection automatically. Whereas anyone can notice bulb for timer delay signal is indicating to power on and bulb for first output is signaling to power

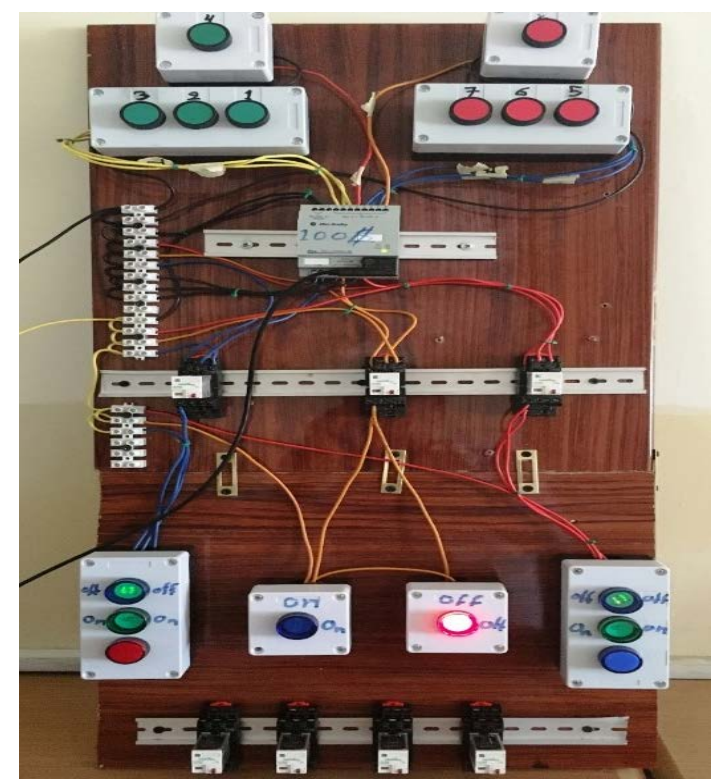

Fig. 7: Electrical control panel interfacing at safety mode

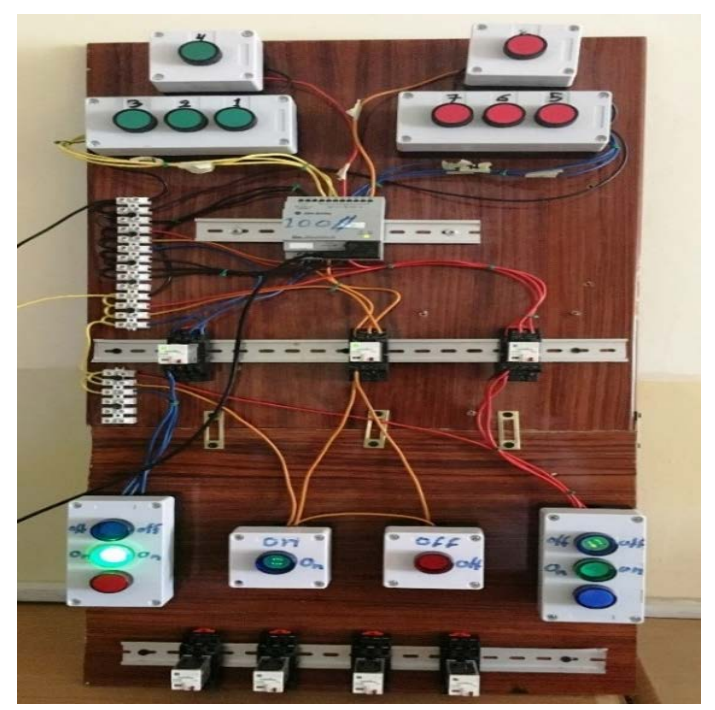

Fig. 8: Star power signal output

off due to star connection time has been finished and bulb for second output is signaling to power on due to delta connection time has been started to work, as displayed in Fig. 9.

Then, the worker press pushbutton 1 to reset circuit, as displayed in Fig. 7 and then returns the previous operation, respectively as the worker needs.

In general star/delta starter is need a lot of expensive components such as coils, conductor, gearbox and overload, etc., this means its circuits would be exorbitant 


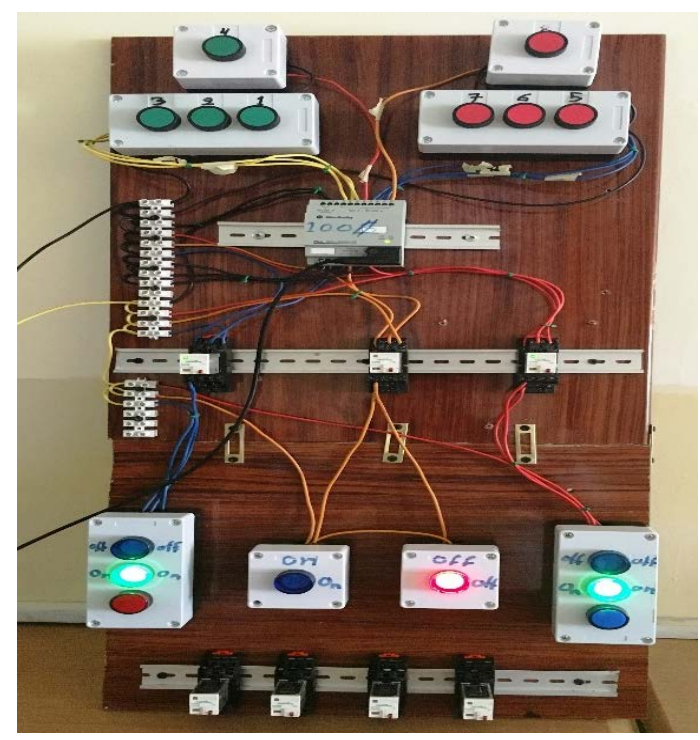

Fig. 9: Delta power signal output

as well as have a time and more effort to finish but not with the proposed circuit by PLC. Whereas it just needs software and little cheap components to finish.

\section{CONCLUSION}

In the past and up to now star/delta starter control circuit is used on starter induction and synchronous drive. Implementation is done obviously and if it compares with Direct Online (D.O.L) circuit, it will satisfactory due to there is no load and loss of current at the beginning start. Therefore, ones have tolook forward to using this method and this theory to get rid of this loss of current. General components that employed to carried out control and power circuit is at the cheap range to any factory. PLC results for star/delta starter experiment are much too worth. Picosoft Software usually works on all windows versions and gives amazing results.

\section{RECOMMENDATIONS}

It is executed logic language like ladder easily. By the sound of it, there is no point in leaving PLC applications for future works.

\section{REFERENCES}

Abdelmoumene, A. and H. Bentarzi, 2014. A review on protective relays developments and trends. J. Energy South. Afr., 25: 91-95.

Alexander, C. and S. Matthew, 2012. Fundamentals of Electric Circuits. 5th Edn., McGraw-Hill Education, New York, USA., ISBN:9780073380575, Pages: 992.
Alphonsus, E.R. and M.O. Abdullah, 2016. A review on the applications of Programmable Logic Controllers (PLCs). Renewable Sustainable Energy Rev., 60: 1185-1205.

Bryan, L.A. and E.A. Bryan, 1997. Programmable Controllers: Theory and Implementation. Industrial Text Company, Atlanta, Georgia, USA., ISBN:9780944107324, Pages: 1035.

Dunga, P.K.D., M.S. Hussain and S. Bhindwa, 2014. Study of PLC automation. Intl. J. Electr. Electron. Comput. Res. Dev., 1: 6-8.

Goh, H.H., M.S. Looi and B.C. Kok, 2009. Comparison between direct-on-line, star-delta and auto-transformer induction motor starting method in terms of power quality. Proceedings of the International Conference on Multiconference of Engineers and Computer Scientists Vol. 2, March 18-20, 2009, Hong Kon, China, ISBN:978-988-17012-7-5, pp: 18-20.

Hammid, A. T. and M.H. Sulaiman, 2017. Optimal long-term hydro generation scheduling of Small Hydropower Plant (SHP) using metaheuristic algorithm in Himreen lake dam. Proceedings of the MATEC Web Conference on UTP-UMP Symposium on Energy Systems (SES'17) Vol. 131, October 25, 2017, EDP Sciences, Les Ulis, France, pp: 04017-04021.

Hammid, A.T., 2013. Applications of tuning control actions for the efficient load/frequency control in steam turbine. Intl. J. Curr. Eng. Technol., 3: 1895-1898.

Hammid, A.T., 2016. Direct on line starter motor and reverse system in Allen-Bradley PLC. Diyala J. Pure Sci., 12: 132-148.

Hammid, A.T., A.K. Bhardwaj and S. Prakash, 2013. Design remote power control $\mathrm{I} / \mathrm{O}$ data acquisition system and control on home automation. Intl. J. Electron. Commun. Comput. Eng., 4: 528-535.

Hammid, A.T., M. Hojabri, M.H. Sulaiman, A.N. Abdalla and A.A. Kadhim, 2016. Load frequency control for hydropower plants using PID controller. J. Telecommun. Electron. Comput. Eng., 8: 47-51.

Hammid, A.T., M.B.H. Kadhim, A.A. Sulaiman, A.N. Kareem and K.J. Jadaa, 2017c. Priority of kaplan turbine and small hydropower plants over other resources: An overview. J. Eng. Appl. Sci., 12: 8695-8705.

Hammid, A.T., M.H.B. Sulaiman and A.A. Kadhim, 2017 b. Optimum power production of Small Hydropower Plant (SHP) using Firefly Algorithm (FA) in Himreen Lake Dam (HLD), Eastern Iraq. Res. J. Appl. Sci., 12: 455-466.

Hammid, A.T., M.H.B. Sulaiman and A.N. Abdalla, 2017a. Prediction of small hydropower plant power production in Himreen Lake Dam (HLD) using artificial neural network. Alexandria Eng. J., 2017: $1-11$. 
Iovev, A.N. and P.I. Yakimov, 2015. Application of PLC as a gateway in a network of smart power transducers. IFAC. Pap. OnLine, 48: 95-98.

Kato, M., K. Orikawa, J.I. Itoh and N. Saitoh, 2013. Fast starting method using both inverter and delta-star starter for weaving machine drive systems. Proceedings of the 2013 1st International Conference on Future Energy Electronics (FEEC), November 3-6, 2013, EEE, Tainan, Taiwan, ISBN:978-1-4799-0073-2, pp: 211-216.
Mazidi, M.A., 2013. The 8051 Microcontroller and Embedded Systems using Assembly and C: United States. 2nd Edn., Pearson, London, UK.,.

Naeem, W., 2009. Concept in Electric Circuits. Bookboon, London, UK., ISBN:978-87-7681-499-1, Pages: 86.

Papa, S., W. Casper and T. Moore, 2013. Securing wastewater facilities from accidental and intentional harm: A cost-benefit analysis. Intl. J. Crit. Infrast. Prot., 6: 96-106. 